\title{
Perceptions of the Sexual Assault Exam in the Emergency Department Setting
}

\author{
Ann Thomas ${ }^{1}$, Michelle A. Lyn ${ }^{2,3}$, A. Chantal Caviness ${ }^{2}$, Deborah C. Hsu², Xuan G. Tran ${ }^{4}$ and \\ Angelo P. Giardino ${ }^{*, 2,3,4}$ \\ ${ }^{I}$ George Washington University School of Medicine, Children's National Medical Center, USA \\ ${ }^{2}$ Baylor College of Medicine, Houston, TX, USA \\ ${ }^{3}$ Texas Children's Hospital, Houston, TX, USA \\ ${ }^{4}$ Texas Children's Health Plan, Houston, TX, USA
}

\begin{abstract}
Objective: The purpose of this study is to determine how pediatric patients and/or their parents being interviewed and examined for suspected sexual assault perceive their experiences in the emergency department.

Methods: A prospective study was conducted at an emergency department. A convenience sample was enrolled from September 2007 to February 2009. At the completion of the medical examination, patients and/or parents were asked to take part in a survey.

Results: A total of 87 completed questionnaires were collected; 50 completed by parents/guardians and 37 completed by the patients; 14 patients had both parent and patient questionnaires completed. Of all 87 respondents, $74 \%$ of parents and $65 \%$ of the patients rated the overall quality of care as excellent, $90 \%$ of parents and $70.3 \%$ of patients rated the physician kindness as excellent, and $90 \%$ and $86.5 \%$ respectively rated the nurse kindness as excellent. Of the 50 patients, $35.1 \%$ patients found the exam sometimes or very painful and $40.5 \%$ found the exam scary sometimes to extremely scary. Patients who perceived the exam painful or scary did not rate their quality of medical care as lower than those who did not find the exam painful or scary, $\mathrm{p}=0.513$ and $\mathrm{p}=0.800$ respectively.

Conclusions: Encouragingly, the emergency department environment did not cause higher levels of distress, anxiety or discomfort than other groups of patients evaluated in child abuse evaluation centers.
\end{abstract}

Keywords: Child sexual abuse, emergency department setting, medical evaluation for child sexual abuse, patient experience, perception of sexual assault exams, suspected sexual abuse.

\section{INTRODUCTION}

Child sexual abuse has been recognized as a serious problem affecting the lives of children and families in our society. Studies have suggested that each year, approximately $1 \%$ of children experience some form of sexual abuse [1]. Recently, the Fourth National Incidence Study determined that $1,256,600$ children experienced some form of maltreatment during the 2005-2006. Of those, 135,300 children were sexually abused [2]. This total reflects an incident rate of 1.8 children per 1,000 children in the general nationwide population.

Children suspected of having been sexually abused, are often referred for medical evaluation of suspected sexual abuse (SSA). The Committee on Child Abuse and Neglect of the American Academy of Pediatrics reviewed the definition and presentation of child sexual abuse and offered an outline of suggestions for the evaluation of suspected victims of

*Address correspondence to this author at the Baylor College of Medicine, Texas Children's Hospital, Texas Children's Health Plan, P.O. Box 301011, NB-8391, Houston, TX 77230-1011, USA; Tel: 832-828-1216; Fax: 832825-8765; E-mail: apgiardi@texaschildrens.org child abuse [3]. This often involves careful questioning regarding the history of events, forensic evidence collection and obtaining laboratory specimens. The medical evaluation includes a complete head to toe physical examination, along with a thorough examination of the anal and genital area to assess for signs of acute and/or chronic trauma. As a result, concerns have been raised that children and adolescents undergoing medical evaluation for suspected sexual abuse may experience further distress and emotional trauma during the medical evaluation, treatment and collection of forensic evidence for suspected sexual abuse.

Several studies have been conducted regarding the emotional impact on the child and/or parent in regard to the anogenital phase of the medical evaluation. Berson et al. studied 514 children evaluated for suspected sexual abuse and described frequent reactions of anxiety, fear, anger, and opposition to the medical examination [4]. Lazebnik et al. investigated how 99 children, ages 3-17, who were examined for SSA perceived their own medical evaluation experiences [5]. They found that the majority of children did not perceive their SSA examination to be strongly negative, however, the children did report greater fear associated with the SSA evaluation compared to an ordinary physician visit. 
Additionally, fear and pain associated with the SSA examination contributed to the prediction of intensity of fear about a hypothetical second SSA evaluation. AllardDansereau et al. examined the perceptions of parents of those subjects who presented to an outpatient clinical setting [6]. The sample population consisted of 50 children and their mothers who were referred for evaluation of SSA. Maternal perceptions of their child's reactions to the medical evaluation were assessed with a questionnaire adapted from Lazebnik et al. This study also found mothers to report that their children were more fearful of the SSA visit compared to that of an ordinary medical visit.

Gully et al. developed the Genital Examination Distress Scale (GEDS) to quantify distress during the anogenital phase of the examination [7]. Their findings concluded that children being examined for suspected sexual abuse had greater total and subscale scores for emotional distress during the anogenital phase than the general physical part of the examination. Additionally, greater total and subscale scores for the GEDS correlated positively with physical findings consistent with sexual abuse.

All the previous studies mentioned have consisted entirely of children seen by appointment as opposed to urgent visits. Many of the environments are designed to be familiar and comfortable for children. Several are staffed with child abuse specialists. One might expect that children in an emergency department setting might have a different experience in terms of levels of emotional distress, anxiety and pain. Therefore, we undertook this study to determine how pediatric patients and/or their parents being interviewed and examined for suspected sexual assault perceive their experiences in the emergency department (ED) independent of the severity of the assault.

\section{METHODS}

A prospective study was conducted at Texas Children's Hospital (TCH) ED, a tertiary care children's hospital located in Houston, Texas with over 85,000 ED visits/year and approximately 650 visits/year for suspected sexual assault. Approximately half of the children and adolescents evaluated for suspected sexual abuse in the TCH ED have a forensic evidence kit completed. A convenience sample of patients was enrolled from September 2007 to February 2009. The study was approved by Baylor College of Medicine institutional review board (IRB).

\section{Materials}

The survey instrument was adapted using items from 1) a questionnaire developed by Lazebnik et al. [5] and 2) a validated instrument used by $\mathrm{TCH}$ to evaluate hospital-wide patient satisfaction. (See APPENDIX) Content and construct validity were achieved through a multi-step process including review by an expert panel, consisting of pediatric emergency medicine and child abuse specialists, and a focus group. Through this process, the survey instrument was revised to result in the final version used in the study. Surveys were developed in English at a 6th grade reading level and translated into Spanish. In order to decrease the patients' distress, patients' demographic information and details of the alleged assault were abstracted from their medical records.

\section{Sample}

The study populations were children and/or their parent(s) who were presented at the TCH ED with suspected sexual assault less than 96 hours. Patients and parents had to be English or Spanish speaking. For patients who were 12 years old or younger, their parent(s) were recruited for the survey. For patients who are older than 12 year of age, they were given the opportunity to participate in the study by completing their own survey. Additionally, the parents of these patients were also given and opportunity to complete their own survey also. Patients were excluded from the study if the suspected sexual abuse was more than 96 hours, spoke a language other than English or Spanish, or had a history of an underlying psychiatric illness.

* Of note, in Texas, law enforcement requires the forensic evidence kit is completed on sexual assault investigation up to 96 hours for suspected contact.

\section{Procedures}

At the completion of the standard of care, the following steps were taken to recruit the study population:

1. For patients who are 12 years of age or younger, the patients' parents were recruited for the patient survey,

2. For patients who were 12 years of age or older, both patients and parent(s) were recruited for the survey.

The physician or nurse from the patient care team conducted the recruitment for the survey. Once the patient and/or their parent(s) agreed to participate in the study, a written informed consent was obtained. Finally, the patient or parent was asked to fill out the survey. The completed survey is then collected by the physician or nurse and placed in a sealed box. Using the patient's medical record number and a data recording sheet the demographics and description of the assault were then documented. In order to decrease the patients' distress, information about assault including the demographic information (age, gender, race), and details of the alleged assault (time between most recent assault and examination, relationship of perpetrator to patient, frequency of victimization, and history of penetration). All patientrelated identifying variables were removed from the study.

\section{Data Analysis}

Data analysis was performed with SPSS 17 (SPSS Inc., Chicago, Ill.) Descriptive statistics (means and frequency) were calculated for the demographic and clinical features of study participants. Using Chi-Square Tests, the perception of overall medical care was statistically compared between patients who did and did not find the exam to be painful or scary. Survey responses for parents/guardians in the study were compared to $\mathrm{TCH}$ parental satisfaction survey responses over the study time period. Only parental/guardian responses could be compared because $\mathrm{TCH}$ measures parental/guardian satisfaction as part of its on-going qualityimprovement activities. For these comparisons, 95\% confidence intervals were estimated for study parent/guardian question responses: responses were considered to be similar if the $\mathrm{TCH}$ parental satisfaction survey response fell within the study parent/guardian survey response $95 \%$ confidence interval. 


\section{RESULTS}

A total of 73 SSA patients who evaluated in the ED agreed to participate in the study. Of the 73 patients who participated in the study, 50 parents completed the quality surveys and 37 patients completed the quality surveys for a total of 87 completed survey (See APPENDIX). Of the 73 patients, 55 had a full forensic evidence collection kit completed. Patient characteristics and demographics abstracted from patient medical records are described on Table 1 . The demographic showed that $28.8 \%$ were less than 6 years of age, $30.1 \%$ were aged $6-13$, and $30 \%$ were over 13 years of age, $79.5 \%$ were female, and $20.5 \%$ were male. $61.6 \%$ knew the perpetrator, and $60.3 \%$ were evaluated within 48 hours of the assault (see Table 1).

Using the subset of 14 completed surveys that had both a parent and a child questionnaires completed, we assessed if there was any difference between patients and parents responses in the overall quality of care, physician kindness and nurse using Wilcoxon Signed-Rank Test. All responses from three questions are not statistically significantly different between patients and parents.

Additionally, of the 50 parent surveys completed, 35.1\% of the parents found that the exam sometimes or very painful and $40.5 \%$ found the exam scary sometimes to extremely scary. Of the 37 patients surveyed, those who perceived the exam painful or scary did not rate their quality of medical care as lower than those who did not find the exam painful or scary, $p=0.513$ and $p=0.800$ respectively.

Finally, SSA parents/guardians survey responses were compared to the general TCH emergency department (ED) parental satisfaction survey responses over the study time period. Based on this comparison, the assessment of overall medical quality was similar for both groups while the assessment of explanations and nursing care was different between groups. Of the 50 parents in our study, $90 \%(95 \%$ CI 78.2\%-96.7\%) rated nursing care as excellent compared to $58.9 \%$ of the general ED parental surveyed and $86 \%$ (95\% CI $73.3 \%-94.2 \%)$ rated explanations of tests and the exam as excellent compared to $54.2 \%$ respectively of parents of all children seen in the ED (Fig. 1).

\section{DISCUSSION}

Examination of the genitalia of sexually abused children can be a stressful experience. Previous studies have shown that many patients experience fear or anxiety associated with the medical examination of the sexual assault evaluation. Findings of this study suggest that patients and parents perceive their overall experience in the ED setting as positive. Our study found that $81 \%$ of the children found their ED visit to be a better experience than their routine medical visits. Even when the exam was perceived as scary or painful, patient satisfaction with care remained high. Our study also found that $98 \%$ of our patients found their nursing care, which consisted of a dedicated SANE team, to be excellent to very good in the emergency department. A recent study by Bechtel et al. revealed that patients who had been sexually assaulted received more sexually transmitted diseases testing, pregnancy prophylaxis, and referrals to a rape crisis center when a SANE nurse was present [8]. Not
Table 1. Patient Characteristics and Demographics

\begin{tabular}{|c|c|c|}
\hline Characteristic & & All Patients $(\mathrm{N}=73)$ \\
\hline & $\mathrm{n}$ & Percentage (\%) \\
\hline \multicolumn{3}{|l|}{ Age } \\
\hline 0-5 Years & 21 & 28.8 \\
\hline 6-13 Years & 22 & 30.1 \\
\hline$>13$ Years & 30 & 41.1 \\
\hline \multicolumn{3}{|l|}{ Gender } \\
\hline Male & 15 & 20.5 \\
\hline Female & 58 & 79.5 \\
\hline \multicolumn{3}{|l|}{ Race/Ethnicity } \\
\hline African-American & 14 & 19.2 \\
\hline Hispanic & 36 & 49.3 \\
\hline Caucasian & 12 & 16.4 \\
\hline Other & 3 & 4.1 \\
\hline Missing & 8 & 11 \\
\hline \multicolumn{3}{|l|}{ Time Since Assault } \\
\hline$<24$ Hours & 27 & 37 \\
\hline 24 - 48 Hours & 17 & 23.3 \\
\hline 48 - 72 Hours & 7 & 9.6 \\
\hline$>72$ Hours & 3 & 4.1 \\
\hline Unknown & 19 & 26 \\
\hline \multicolumn{3}{|l|}{ Perpetrator } \\
\hline Relative & 20 & 27.4 \\
\hline Friend/Boyfriend & 25 & 34.2 \\
\hline Stranger & 17 & 23.3 \\
\hline Unknown & 3 & 4.1 \\
\hline \multicolumn{3}{|l|}{ Assault Frequency } \\
\hline 1 & 25 & 34.2 \\
\hline $2-5$ & 5 & 6.8 \\
\hline$>5$ & 1 & 1.4 \\
\hline Unknown & 42 & 57.5 \\
\hline \multicolumn{3}{|l|}{ Penile Penetration } \\
\hline No & 42 & 57.5 \\
\hline Yes & 31 & 42.5 \\
\hline \multicolumn{3}{|l|}{ Other Penetration } \\
\hline No & 51 & 69.9 \\
\hline Yes & 22 & 30.1 \\
\hline
\end{tabular}

only does this emphasize the need for specially trained medical personnel but may also provide improved patient care compared to emergency or outpatient settings who do not have SANE programs. 


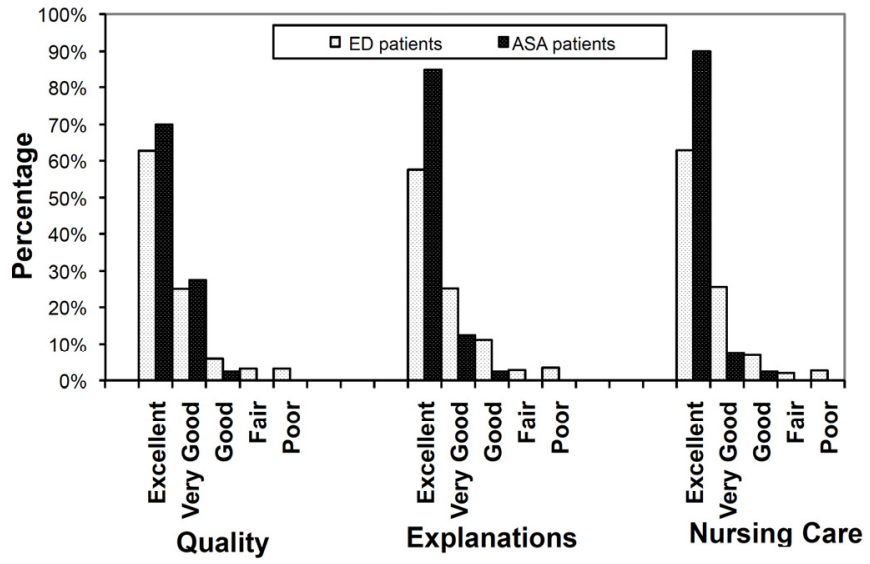

Fig. (1). Comparison of Parental Survey: All ED patient vs. Alleged Sexual Assualt (ASA) patients.

Although these findings are reassuring, this study had several limitations. The survey instrument used was not a previously validated and could have been an imprecise measuring tool. However, since there are few previous studies evaluating patients in the ED, the results found in this study are encouraging. Similarly, our survey answers were compared to survey answers given to parents who visit the emergency department from a validated instrument used by $\mathrm{TCH}$ to report patient satisfaction levels. In comparison, those answers again demonstrated that parents of SSA patients versus parents of all ED patients rated their overall care as excellent $74 \%$ vs $60.2 \%$ respectively. Also, the physician or nurse from the patient care team who were collecting these data was not independent from the statff giving the examination, which may impact the results. Finally, the sample may not be a respresentive of the overall population since there is a lack of data on how many children/parents were approched and recruited for the study.

The ED at $\mathrm{TCH}$ during this study period saw approximately 650 patients per year for suspected sexual assault and questionnaires were collected for only 73 patients, the majority of which were English speaking. Due to the high volume of patients seen in the ED, many patients were not asked to participate in the study and if a Spanish translator was not available, many of the Spanish speaking patients were not given the opportunity to participate. Due to this, findings may not be representative of all patients undergoing evaluation for sexual assault in the ED. However, of the 73 patients approached, 55 had a forensic evidence collection kit completed. Annually, the TCH ED performs approximately 310 kits. Since the majority of our patients had evidence collection kits performed, it represents a reasonable sampling of that population and may be more representative of patients who present to the ED and need more invasive testing performed. All children who undergo forensic evidence collection also had colposcopy with digital camera performed. Previous studies have also demonstrated children who underwent video colposcopy exhibited less distress and anxiety during the genital examination. Mears reported that $78 \%$ of her patients found that the medical examination with colposcopy "was helpful," a "good idea" and helped them "feel better." [9]
Edinburgh et al. found that adolescents evaluated at the designated outpatient Child Advocacy Center's received more thorough health assessment, were more likely to have documented genital injuries, and were more likely to be treated or tested for sexually transmitted illnesses than those who received care in community settings, including emergency departments [10]. Furthermore, those adolescents received more referrals for counseling than those teens evaluated in community settings. Although Edinburgh's study included all community settings, future studies comparing emergency departments to outpatient child advocacy centers may be warranted to compare patient and parent perceptions and determine the best setting for sexual assault examinations. Encouragingly, at least for this sample of patients, the ED environment did not cause higher levels of distress, anxiety or discomfort than other groups of patients evaluated in child abuse evaluation centers.

\section{CONFLICT OF INTEREST}

The authors confirm that this article content has no conflicts of interest.

\section{ACKNOWLEGEMENTS}

Special acknowledgement to the sexual assault nurse examiner (SANE) team at Texas Children's Hospital.

\section{APPENDIX}

\section{Patient's Gender \\ 口 Male \\ a Female}

Date of Birth:

\begin{tabular}{|c|c|}
\hline . Whi & $h$ of the foll \\
\hline$\square$ & Patient \\
\hline a & Parent \\
\hline a & Guardian \\
\hline a & Other \\
\hline
\end{tabular}

\section{Please rate the overall quality of the medical care your child received during their visit: \\ a Excellent \\ Very Good \\ G Good \\ a $\quad$ Fair \\ a Poor}

3. Please rate the kindness and gentleness of the physician:
口 Excellent
V Very nice
a Nice
口 Fair
口 Poor

4. Please rate the kindness and gentleness of the nurse:
$\begin{array}{cl}\square & \text { Excellent } \\ \square & \text { Very nice } \\ \square & \text { Nice } \\ \square & \text { Fair } \\ \square & \text { Poor }\end{array}$


5. Please rate how well the tests and exam were explained to you:

\begin{tabular}{ll}
\hline & Excellent \\
$\square$ & Very Good \\
$\square$ & Good \\
$\square$ & Fair \\
$\square$ & Poor
\end{tabular}

6. How does your child feel about regular doctor's visits?

$\begin{array}{ll}\square & \text { Extremely scared } \\ \square & \text { Very scared } \\ \square & \text { Occasionally/Sometimes scared } \\ \square & \text { Rarely scared } \\ \square & \text { Not scared at all }\end{array}$

7. How did your child do today as compared to other doctor's visits?
a Much better
a little better
a Same
口 A little worse
a Worse

\section{How did your child feel about having pictures taken of} their body?

\begin{tabular}{|ll}
\hline & Extremely scared \\
$\square$ & Very scared \\
$\square$ & Scared \\
$\square$ & Sort of scared \\
$\square$ & Not scared
\end{tabular}

9. Was a Child Life person present?

$$
\text { 口 Yes }
$$$$
\text { a No }
$$

11. What would you consider the one best thing about you or your child's experience at Texas Children's?

\section{What is the single most important thing Texas Children's could have done better?}

\section{REFERENCES}

[1] Center for Disease Control, National Center for Injury Prevention and Control, Child Maltreatment Facts at a Glance Spring 2008 American Academy of Child and Adolescent Psychiatry Facts for Families; May. No 9, 2008.

[2] Sedlak AJ, Mettenburg J, Basena, et al. Fourth National Incidence Study of Child Abuse and Neglect (NIS-4): Report to Congress. Washington, DC: U.S. Department of Health and Human Services, Administration for Children and Families 2010.

[3] Kellogg N, and the Committee on Child Abuse and Neglect. The evaluation of sexual abuse in children. Pediatrics 2005; 116: 50612.

[4] Berson NL, Herman-Giddens ME, Frothinham TE. Children's perceptions of genital examinations during sexual abuse evaluations. Child Welfare 1993; 72 (1): 41-9.

[5] Lazebnik R, Zimet G. Ebert J, et al. How children perceive the medical evaluation for suspected sexual abuse. Child Abuse Negl 1994; 18: 739-45.

[6] Allard-Dansereau C, Herbert M, Tremblay C, Bernard-Bonnin AC. Children's response to the medical visit for allegations of sexual abuse: maternal perceptions and predicting variables. Child Abuse Rev 2001; 10: 210-22.

[7] Gully K, Britton H, Hansen K, Goodwill K, Nope J. A new measure for distress during child sexual abuse examinations: the genital examination distress scale. Child Abuse Negl 1999; 23: 6170 .

[8] Bechtel K, Ryan E, Gallagher D. Impact of sexual assault nurse examiners on the evaluation of sexual assault in a pediatric emergency department. Pediatr Emerg Care 2008; 24: 442-7.

[9] Mears C, Heflin A, Finkel M, Deblinger E, Steer R. Adolescents; responses to sexual abuse evaluation including the use of video colposcopy. J Adolesc Health 2003; 33: 18-24.

[10] Edinburgh L, Saewyc E, Levitt C. Caring for young adolescent sexual abuse victims in a hospital-based children's advocacy center. Child Abuse Negl 2008; 32(12): 1119-26. 